\title{
Feelings and Experiences of Counseling Practicum Students and Implications for Counseling Supervision
}

\author{
Dr. Norwati Mansor \\ Institute of Education, International Islamic University Malaysia \\ nurmansur@gmail.com / norwati@iium.edu.my
}

\section{Dr. Wan Mazwati Wan Yusoff}

Kulliyyah of Islamic Revealed Knowledge and Human Sciences, International Islamic University Malaysia wanmazwati@gmail.com /wanmazwati@iium.edu.my

\section{Doi:10.5901/jesr.2013.v3n7p731}

\section{Abstract}

This study focuses on Counseling Practicum students' feelings and experiences during the Bachelor in Education program at International Islamic University. The students, who were in Guidance and Counseling specialization, had to go through two phases of training; practicum for seven weeks and internship for fourteen weeks. These training periods provide them an opportunity to apply related theories and techniques that they had learnt during three to four years of their studies. The participants for this study consisted of ten third year students from Guidance and Counseling course. This qualitative research adopted students' journals, group counseling supervision, documentations, case presentation and interviews as the data resources to reveal rich description of the students' feelings and experiences. The findings indicate five main themes derived for discussion which include nervousness, ability and counseling skills, negotiating students' or clients' perceptions, lack of confidence in application of theories, and task completion. Further, this study provides an insight for supervisors to highlight issues and challenges in assisting future trainee counselors.

Keywords: counseling practicum, supervision, teacher education, feelings and experiences

\section{Introduction}

Counseling practicum is a vital part of counselor education through experiential learning where trainees learn how to reflect and analyze their concrete experience gained in practicum to form and expand their configuration of meaning which they could further validate through action and experimentation (Kolb, 1984). The main aim of this process of experiential learning is to transform thinking and action of themselves as counselor so that they could effectively affect thinking and action of their clients. In other words counseling practicum gives trainee counselors an opportunity for change and growth personally and professionally. Education and Technical Training Committee and Board of Counselor Malaysia (2003) define counseling practicum as a supervised clinical experience of trainee counselors for the purpose of building and expanding their basic counseling skills and integrating their theoretical professional knowledge into practice. Counseling practicum provides the opportunity to evaluate trainees' ability to apply knowledge and skills acquired from course works with clients at the school setting. During the counseling practicum, trainees will experience applying appropriate theoretical knowledge to appropriate cases; practicing their counseling skills; building rapport with clients and other stakeholders; negotiating their own perception towards others and others' perceptions towards them; dealing with their own psychological needs and challenges in the process of fulfilling expectation of others and their own selves.

Developmental growth materializes when a person experienced a situation that provides adequate cognitive disequilibrium (Kohlberg, 1981) provided that such person has the necessary prerequisites and resources to effectively negotiate the experience. Counseling practicum and internship could serve as a lived experience which provides sufficient disequilibrium where trainee counselors are given the chance for personal and professional development (Borders, 1998). These lived experiences are invaluable empirical data that could be studied and analyzed to give better understanding of the subjective experiences lived by trainee counselors during their practicum and internship for the purpose of devising more effective learning contracts between supervisors and supervisees.

However, studies on developmental growth of counselors were less favorable compared to studies on the 
application of theories. According to two prominent researchers in counselor and therapist developmental growth, Orlinsky and Ronnestad (2005), concentration on investigating the effectiveness of some therapeutic techniques may be one of the contributing factors to the lack of research in personal and developmental growth of trainees. This is rather surprising since researches have shown that the difference in outcome across methods was smaller compared to the outcome among counselors or therapists within methods (Ronnestad and Skovholt, 2003). This means that the counselor is more important than the method that he or she uses. Therefore, understanding the counselor personal and developmental growth is significant for counselor education and training. The first step in understanding of counselors' developmental growth is to examine the feelings and experiences of trainees. However, literatures that focus on the developmental process as experienced by trainees proved lacking (Grafanaki, 2010; Luke and Kiweewa, 2010).

Bachelor of Education (BED) in Guidance and Counseling is a new program offered at International Islamic University Malaysian (IIUM). The first batch of students enrolled in this program was in 2007. Apart from fulfilling the university and Ministry of Education and Higher Learning requirements, the program followed the specifications outlined by Board of Counselor Malaysia (Lembaga Kaunselor Malaysia). The students have to complete 250 site hours practicum within seven weeks which consist of 70 hours individual counseling and 40 hours group counseling. While for internship, the students are required to complete 500 hours which consist of 140 hours individual counseling and 80 hours group counseling within 14 weeks.

Since the program is new, the learning experiences gained through counseling practicum provide insight for both students and the BED Guidance and Counseling program. Literature specifically involving IIUM experiences in educating school counselors is scarce. Therefore, this study is significant to provide information for formative evaluation of students and the program.

\section{Methodology}

This study employed qualitative methodology. The main purpose of this study is to explore the subjective experiences of trainee counselors during their practicum. Grafanaki (2010) highlighted that studies which focused on trainees' experiences were lacking because of overemphasis in examining others' perspectives. Narratives of trainee counselors pertaining to their feelings and experiences during their practicum are the main concern of this study.

Participants were 10 BED Guidance and Counseling students who were doing their practicum and internship during semester 2 and semester 3 in 2012/2013 academic year. They voluntarily agreed to participate in this study. They were two male and eight female students who underwent their practicum and internship in secondary schools around Kelang Valley; except one participant who was doing his practicum at the Police Training Center, Kuala Lumpur. Their clients were students of schools which comprised three main racial groups which were Malay, Chinese and Indian; as well as students from Indonesian parents.

The study gathered 3 types of data. The students were required to write journals describing their feelings, experiences and challenges that they have faced during their practicum each week. Further, data was collected during group supervisions. Four group supervisions were conducted. Note taking and audio tape were utilized during group supervisions. Finally, the students were interviewed to gather more stories and to validate their narratives in their journals and during the group supervisions. The interviews were transcribed verbatim. All of the data was analyzed using narrative analysis. Sandelowski (1991) asserted that a set procedure or method to analyze narratives has not yet been developed. According to McLeod and Balamoutsou (2000) researchers are given freedom to create their own method because the step by step methods of how to analyze narratives are unhelpful. However, guidelines as explained by McLeod and Balamoutsou were followed.

\section{Finding and Discussion}

From the trainee counselors' narratives, we understood that the students were nervous before and during the first few weeks of practicum and internship. Their anxiety stemmed from their worries about the acceptance by the school students, teachers and school administrators; the kind of relationship that they would have with clients, site supervisors, teachers, and school administrators; whether they could adapt to the new environment of the school or not; and the perception of the students towards them, trainee counselors.

Izzah's story began with her worries about the adaptation to the new environment and acceptance by the students and the school community. She revealed that "the first thing that crossed my mind at the beginning of internship was whether I could adapt and be a part of the school community. I worried about the acceptance of the administrators and 
the school staff... whether they accept me to be a trainee counselor at their school. I also worried about the acceptance of the students at that school. From my observation, most of the students have negative perceptions about trainee counselors. The students think that trainee counselor has no experience and enough skills and knowledge to conduct counseling sessions. Because of that, most of the students would share their problems with senior counselors rather than trainee counselor".

Similarly, Atif said that "I felt so nervous and uneasy because I always think about what I am supposed to do throughout 14 weeks of internship at a new school. I felt so worried because I did not know what I am supposed to do as I did not really know about this school, teachers, and students. I asked myself what if I could not follow the flow of internship and fulfill its requirements".

Anna added that her nervousness was coming from not only the factors mentioned by Izzah but also the fact that she had never experienced going to multicultural school. She said that "I worried about how I can adapt to the school community and the new school environment. The students of this school comprised of multicultural students which were Malay, Chinese, Indian, aborigines, and Indonesian. I was anxious because I do not know if I have enough skills to deal with students from diverse background and culture... which is different from my own culture. I worry if I made wrong interpretation and say wrong things which touched the sensitivity of other cultures. I worried about how I can conduct group counseling when the members were from different culture, language and religion. I worried if they would not cooperate and share their feelings. I doubt my ability to conduct group counseling where the members were from diverse background, culture, language and religion". Ali shares the same worries for $50 \%$ of the students at the school he was doing internship were Chinese.

The transition from university classroom to school setting was not easy for the first week. Further, they also worried about completing the required contact hours with the client. This is because the client perceived them as not having enough skills and experience to help them.

Suzie stated that "My biggest concern for the first few weeks was whether I could collect 500 site hours as well as completing 140 hours in conducting individual counseling and 60 hours in conducting group counseling. I was worried because it was very hard for me to get clients. This is because the students viewed trainee counselors as inexperienced". Suzie's concerns were also shared by nine of her friends.

However towards the end of practicum and internship they were able to adapt to the new environment and they were happy with the acceptance of the site counselors, teachers and school administrators. Many of them reported that the site supervisor and the school stakeholders accepted them as part of the school community. They also were able to interact with more ease with students from different cultures especially those who were from different religion.

Atif shared that "...after few weeks of internship, I felt that the school accepted me as part of the community, especially the school administrators, teachers, students and other school stakeholders. My relationship with them also has improved and so were my communication skills. I could mingle with senior counselors and other teachers with ease."

Suzie was happy to convey the news that "after few weeks of practicum I was exhausted but happy and this became rather sweet memory for me which I will never forget. I realize that practicum has taught me a lot in terms of building my self-confidence to face challenges of a real professional school counselor. Moreover, after few weeks of practicum, I learned how to build trust as well as build rapport with the school community with diverse background".

Atif could see a few changes in her after few weeks of practicum. "I could adapt to the school environment and my nervousness, anxiety level, negative judgment have reduced. I think I could do better and everything will run smoothly".

Further, the narratives revealed that students were experiencing difficulty to attract the students to get their services. All of them reported that most of the students perceived that those who come to see the counselor were those who have a psychological problem. This perception made it difficult for the trainee counselors to get the clients. The trainee counselors also experience difficulty in meeting the practicum and internship requirements. Since the clients were skeptical toward trainee counselors' abilities therefore they experienced difficulties in completing the required contact hours. They have to work hard in promoting themselves and to make the students aware with their counseling services.

Zul reported that "I need to promote myself to students, as well as to the whole school community. I need to attract people to come for counseling. I felt that it was my responsibility to change students and school community of their perception on counseling services are for problematic students, that is, students with disciplinary problems or students with psychological issues. I have to change their thinking so that they will have positive perception on counseling."

Tini revealed that “...my worries and anxiety are students' perception about counseling sessions. Students viewed 
counseling sessions were for problematic students. It was difficult to get potential clients since I did not get to go to classes to promote my services. Besides, the all-boys school was challenging since they were aggressive and active. They did not listen and like to make noise to distract teachers".

They were also experiencing lack of confidence in their ability to apply the appropriate theories and techniques in handling client problem. Sometime the students applied unsuitable theories and techniques in dealing with client problem. They also reported that they didn't know how to help their client to solve critical issues such as suicide attempt, premarital sex, drug, and bullying. Furthermore, they experienced lack of skills in questioning especially in probing or exploring the client root problem.

Atif revealed that "...sometimes I did not know what to do to explore their exact problems, as well as to pursue them to talk. I am not sure how can I get them to talk and I wonder whether I know enough theory to apply in counseling sessions. Even after a few months of practicum, I still felt anxious especially when I have to face critical issues. Reality is really scary. It was scarier when I was not confident that I have matched the appropriate theory to deal with certain issue. However, for critical issues, I referred to my supervisor. The skills that I really need to help me become a better counselor are probing and application of theoretical orientation in terms of doing treatment plans. It is really meaningful to me to be able to explore problems in detail. Sometimes I just explore client's problem on the surface then I made interpretation about the client's problem. However, the real problem was not actually but something else".

Ruha said that "...I was struggling to apply counseling techniques during my sessions with my clients. I have tried my best to improve my techniques and approaches so that I would not misinterpret and make any mistake particularly in diagnosing my clients' problems. Sometimes I made revision regarding counseling techniques and approaches that I can use and apply in my sessions with clients. Indeed, I do really need some guidelines".

Anna's experience was similar. She mentioned that "I felt a bit worried about appropriate techniques and theoretical orientation that is suitable with $\mathrm{mw}$ in dealing with various client issues. This thing is always haunting me and playing around in my mind. I am still making a great effort to improve my skills in using appropriate counseling techniques as well as to enhance my theoretical orientation. I lack counseling micro-skills such as active listening, accenting and amplifying, reflection of content and feeling and many more. Through my experience with my clients, I identified that I am not good in exploring in depth about my client's problems and feelings."

Tini shared that "After I have completed my session with my clients, I asked myself whether I have used the right techniques and applied appropriate theories. I reflected on whether I was able to make them realize their problems, as well as whether I have helped them to solve their problems. I asked myself whether I can be an effective counselor for my next clients".

Hazmi reported that "I was lacking in counseling skills and competencies. I am afraid that my counseling sessions became meaningless and led to nowhere. I am afraid that my counseling sessions became small talk or I would get lost in my clients' stories. I think that I need to improve my mental and psychological stamina to make me always ready to serve my clients".

Trainee counselors were expected to be substitute teachers especially for teachers who were on medical leave and who were involved in meeting and courses outside the schools. Most of the trainee counselors experience difficulties in classroom management. Some of them do not know how to control students' disruptive behaviors. Thus, in the substitute classes they were not able to deliver their planned classroom guidance.

Amy's experiences were quite stressful. "I have anxieties and worries especially when it came to going for substitute class. We were supposed to do classroom guidance but I have difficulties in handling the classroom guidance. They never gave attention and made noise. I don't know how to get their attention. When they misbehaved, I just approached them one by one and I will write their name in record book and they will get demerit".

Izzah also shared the same concerns. "Handling classroom guidance was very challenging to me because they were very active and for the first day we met, only two students were in class. They were noisy and went out from classroom without permission. I have difficulty to handle them, I need classroom management skills".

Tini reported that "even though I have experience but I still have anxiety during relief class. This is because some students did not really give cooperation when I was doing activities in class. I feel like I failed in controlling the class".

Towards the end of practicum and internship, the trainee counselors reported that they have gained some valuable experiences which helped them in the process of becoming professional counselor. As they progressed along, they realized that they could handle anxiety and stress that came their way better and they were able to improve their confidence level. Even though they were still struggling to be more confident in applying counseling skills and theoretical knowledge, practicum and internship has provided them the opportunity to experience a professional life of school counselors. 
Atif said that "I totally agreed that internship experiences and supervision have helped me in building my skills and self-confidence. Internship helped me to understand my real role as school counselor first hand." Izzah agreed that she has "learned valuable lessons to become a professional school counselor. I learned and always to ask senior counselor to handle big cases like drug abuse, rape victim, and family crisis. I also realized that I need to improve on a lot of things such as communication skills. As a counselor, I need to be good in interpersonal skills. Practicum, internship and supervision helped me much in terms of counseling skills. The time of practicum and internship is the time for me to gain as much experiences as I can in the process of me becoming a professional counselor. Through internship also I can discover the roles of a school counselor."

Counselor education begins with pre-practicum course works that are necessary to prepare students to become a professional counselor. However prepared a student is in classroom environment, the feeling of nervousness and anxiety is normal when the student is given his or her first client. Movement to the unknown role of a 'real' school counselor is psychologically daunting for trainee counselor as he or she has to deal with a variety of uncertainties and expectations from his or own self, supervisor, and school community including students as his or her clients. The first experience with a client creates self-doubt. All of the students in this particular study reported that they asked themselves questions such as: "Am I able to help my client to settle their problem? Have I used appropriate theories and techniques? What if I use the wrong techniques? What if I misinterpret and misdiagnose? Stoltenberg (1981) described trainee counselors as neurosis bound and has a tendency to imitate other counselors including their own supervisors or their model counselors. They lack individuality because of lack of experience. They seem unable to bridge the gap between theory and practice. At this level, trainee counselors are dependent on their supervisors, professors and senior counselors. This led them to appreciate support and encouragement from the experienced supervisors and counselors (Ronnestad and Skovholt, 2003).

\section{Implication for Supervision}

The development of trainee counselors' theoretical knowledge, counseling skills, and awareness of counseling process are the main purposes of counseling practicum and internship. The insight gained from present exploration of trainee counselors' feelings and experiences during counseling practicum informed practicum supervisors and curriculum developers in planning and implementing formative evaluation. The findings indicated that counseling students having most difficulties in executing counseling abilities and practicing counseling skills; they also faced challenges in applying theoretical knowledge; and they lack skills in classroom management. Furthermore, the trainee counselors were anxious during the first few weeks of their practicum and internship because of several factors including the anxiety that they could not help their clients to solve critical issues.

To alleviate nervousness during the first few weeks of practicum and internship, university supervisors should give briefing one week before the practicum or internship. Supervisor should highlight feelings that may encounter during the first few weeks of practicum and internship. The supervisors could make clear their expectation from the students as well as expectation of the school from the students. Positive feedback and encouragement from supervisors could also calm their anxiety and nervousness (Ronnestad and Skovholt, 2003). Further, supervisors should highlight critical issues that trainee counselors may encounter during their practicum to prevent the feeling of shocked during the counseling process. For critical issues, networking and support group created by supervisors could be established online as well as telecounseling for immediate supervision from supervisors.

The university supervisors should highlights the tasks that they have to do during the practicum and internship such as promoting their services using poster and brochures. Supervisors should highlight the perception of the trainees' prospect clients. Therefore, trainee counselors are expected to use their creativity in persuading clients to seek their services. It would be helpful if the supervisors could show the trainees some examples of brochure, posters and other promotion techniques done by their previous supervisees. Samples of needs assessment, program proposals and class guidance should be made available for students. Another important task that trainee counselors required to do is to relief class when the class teacher was not present. However, trainee counselors' lack of skills in managing students' disruptive behaviors had resulted in failure of delivering planned class guidance and feeling of disappointment. Therefore, specific training in classroom management skills and handling classroom disruptive behaviors should be provided by university supervisors prior to counseling practicum.

In order to assist students in counseling skills and in applying theoretical knowledge, supervisors could hold prepracticum seminar or workshop. In this pre-practicum workshop, students will be exposed to various simulations and role plays in dealing with common as well as critical issues faced by secondary school students. 


\section{Conclusion}

Trainee counselors started to experience their role as school counselors with feeling of apprehension and anxiety. As they progressed through the practicum and internship, they anxiety level decreases but their self-doubt on their counseling skills and application of theoretical knowledge took a longer time to overcome. However, their confidence level increases but not to the extent that they become independent from their supervisors. From the stories of the interns, we understood that they have gained a very significant tool of learning which is reflection. Reflection on their experiences enabled them to be aware of their own selves and others and this is vital for their own professional development.

\section{Reference}

Borders, L. D. (1998). Ego development and counselor development. In P. M. Westenberg, A., Blasi, \& L. D. Cohn (Eds.), Personality development: Theoretical, empirical, and clinical investigations of Loevinger's conception of ego development (pp. 331-343). Mahwah: NJ: Lawrence Erlbaum Associates.

Grafanaki, S. (2010). 'Counsellors in the making': Research on counseling training and formative experiences of trainee counsellors. Counselling \& Psychotherapy Research, 10(2), 81-82.

Jawatankuasa Teknikal Pendidikan dan Latihan Lembaga Kaunselor (2003). (Education and Technical Training Committee and Board of Counselor ,2003). Piawai dan kelayakan latihan kaunselor. Kuala Lumpur: Lembaga Kaunselor Malaysia.

Kohlberg, L. (1981). Essays on Moral Development, Vol. I: The Philosophy of Moral Development. Harper \& Row.

Kolb, D. (1984). Experiential Learning. Experience as the Source of Learning and Development,

Englewood Cliffs, N.J.: Prentice-Hall.

Luke, M., \& Kiweewa, J. M. (2010). Personal growth and awareness experiences of counseling trainees in an experiential group. Journal for Specialists in Group Work, 35(4), 365-388.

McLeod, J. \& Balamoutsou, S. (2000) A method for qualitative narrative analysis of psychotherapy transcripts. In Frommer J, Rennie DL (Eds), Qualitative Psychotherapy Research: Methods and Methodology. Berlin: Pabst.

Orlinsky, D. E., \& Rønnestad, M. H. (2005). How psychotherapists develop: A study of therapeutic work and professional growth. Washington, DC: American Psychological Association.

Ronnestad, M. H. \& Skovholt, T. M. (2003). The Journey of the Counselor and Therapist: Research Findings and Perspectives on Professional Development. Journal of Career Development, 30(1), 5-44.

Sandelowski, M. (1991). Telling Stories: Narrative Approaches in Qualitative Research.

Image: Journal of Nursing Scholarship. 23(3), 161-166.

Stoltenberg, C. (1981). Approaching Supervision from a Developmental Perspective: The Counselor Complexity Model. Journal of Counseling Psychology, 28(1), 59-65. 